Thus there were only four patients who had not received lithium, lorazepam or anticonvulsants and even they were tested over a range of 3-24 months after starting clozapine. It is acknowledged that $60 \%$ of patients take a year to respond to clozapine (Meltzer et al, 1989) and it is therefore possible that even these four patients had not had a long enough trial of the drug.

My own experience of lithium and clozapine was one patient who, after the lithium was stopped, went on to pass school examinations and recommence driving. He remains well on clozapine monotherapy after nearly three years.

I would suggest that there is no conclusion to be drawn from this paper, except that it is impossible to 'dissect' the causes of cognitive deficits in polypharmacy patients (taking preparations such as lithium) who may also have brain damage. Clozapine not only improves the psychiatric symptoms but also it has been demonstrated over long-term use (13 years) that $39 \%$ of treatment-resistant schizophrenic patients found employment, compared with $3 \%$ before the clozapine was started (Lindstrom, 1989).

Meltzer, H. Y., BAstANI, B., Kwon, K. Y., et al (1989) A prospective study of clozapine in treatment-resistant schizophrenic patients. Psychopharmacology, 99, S68-72.

LinDSTROM, L. H. (1989) A retrospective study on the long-term effect of clozapine in 96 schizophrenic and schizo-affective patients during a 13-year-period. Psychopharmacology, 99, 84-86.

Burnley Health Care Trust

Michael LAuner

Burnley General Hospital

Casterton Avenue

Burnley BB10 2PQ

\section{Mentally ill sex offenders}

SIR: We read with interest Craissati \& Hodes' article on mentally ill sex offenders (Journal, December 1992, 161, 848-849). We have published a paper concerning a series of patients with schizophrenia who had sexually assaulted young women in direct response to command hallucinations (Jones $e t$ al, 1992). We would like to stress the importance of careful examination of the mental states of schizophrenic patients who are charged with such offences, and that this needs to be done as soon as possible after the offence. Craissati \& Hodes suggest that within their group of patients, the majority having schizophrenia, the offences were primarily driven by feelings of sexual disinhibition; recent work from Canada might suggest an alternative hypothesis.

Rogers et al (1990) studied a forensic population which included a group of patients who were found by the research team to exhibit command hallucinations. In $50 \%$ of cases the patients had not reported these symptoms, or denied having them, to the original assessment team. Many patients $(44 \%)$ reported that they frequently responded to hallucinatory commands with unquestioning obedience. We would agree that patients with schizophrenia might commit offences driven indirectly by their psychosis via disinhibition. It is also important to exclude direct effects of their psychosis on offending behaviour via delusions and hallucinations.

It may appear that a patient with schizophrenia has committed a sex offence due to sexual disinhibition. An alternative hypothesis might be that they had command hallucinations at the material time of the offence and this has been missed, or the patients had actively tried to hide these symptoms from the assessment team.

Jones, G. H., Huckle, P. L. \& TANaghow, A. (1992) Command hallucinations, schizophrenia and sexual assaults. Irish Journal of Psychological Medicine, 9, 47-49.

Rogers, R., Gillis, J. R., TURner, R. E., et al (1990) The clinical presentation of command hallucinations in a forensic population. American Journal of Psychiatry, 147, 1304-1307.

The Caswell Clinic

P. L. HUCKLE

Glanrhyd Hospital

Bridgend

University of Wales

G. H. JONES

College of Medicine

Whitchurch Hospital

Cardiff

\section{Mabi bark tea}

SIR: I wish to comment on Drs Hassiotis \& Taylor's paper (Journal, September 1992, 161, 404-407). We have published results of our phytochemical studies of mabi bark tea (Seaforth \& Mohammed, 1988; Seaforth et al, 1992). We have not yet found any "quinoline alkaloids" in mabi bark tea.

Drs Hassiotis \& Taylor stated that the subject "C had boiled it (mabi bark) in water along with sugar and nutmeg", and that she was consuming about two-thirds of a pint of the drink daily during the week before admission. Perhaps the nutmeg could have been responsible for the ill-effects of this particular drink.

The literature describes nutmeg/mace (Myristica fragrans) as the source of hallucinogenic agents! (see Schultes \& Hofmann, 1980; Der Marderosian \& 